\title{
Temperature sensitivity of Swiss and British plant phenology from 1753 to 1958
}

\author{
T. Rutishauser ${ }^{1,2,3, *}$, C. Schleip ${ }^{4}$, T. H. Sparks ${ }^{5,8}, \varnothing$. Nordli $^{6}$, A. Menzel $^{4}$, H. Wanner ${ }^{1,2}$, \\ F. Jeanneret ${ }^{1}$, J. Luterbacher ${ }^{1,7}$ \\ ${ }^{1}$ Institute of Geography, University of Bern, Hallerstrasse 12, 3012 Bern, Switzerland \\ ${ }^{2}$ Oeschger Centre for Climate Change Research (OCCR), Erlachstrasse 9a, 3012 Bern, Switzerland \\ ${ }^{3}$ Unitat d'Ecofisiologia i Canvi Global CREAF-CSIC (Centre for Ecological Research and Forestry Applications), Universitat \\ Autònoma de Barcelona, Edifici C, 08193 Bellaterra, Spain \\ ${ }^{4}$ Chair of Ecoclimatology, Technische Universität München, Am Hochanger 13, 85354 Freising, Germany \\ ${ }^{5}$ NERC Centre for Ecology and Hydrology, Monks Wood, Abbots Ripton, Huntingdon, Cambridgeshire PE28 2LS, UK \\ ${ }^{6}$ Norwegian Meteorological Institute, Box 43, Blindern, 0313 Oslo, Norway \\ ${ }^{7}$ Department of Geography, Climatology, Climate Dynamics and Climate Change, Justus Liebig University, 35392 Giessen, Germany
}

${ }^{8}$ Present address: 68 Girton Road, Girton, Cambridge CB3 0LN, UK

\begin{abstract}
Recent changes in springtime plant phenological records are likely unprecedented and have been attributed to anthropogenically induced temperature change. In Europe, a major synchronous break in phenological time series in the 1980s was found in numerous studies; however, few of these studies put these breaks into a historical perspective. We present evidence from 2 historical plant phenological records from northern Switzerland and the UK from 1753 to 1958. Monthly mean temperature measurements are available for the same regions. We assess whether synchronised changes in temperature and plant phenological records and recent temperature impacts are unprecedented at the end of the 20th century. We compare the temporal evolution of plant phenological spring indices (PPSI) and temperature series, search for common shifts and change-points by applying Pettitt's test and a Bayesian model comparison approach, and discuss changing temperature sensitivity for both localities. Results show that the Swiss records contain half the phenological variability ( $\mathrm{SD}=5 \mathrm{~d}$ ), compared to the UK observations, but higher temperature variability in winter and spring. There is a lack of synchronous shifts and one-point-changes in phenological and temperature series prior to 1958 in contrast to the widespread changes in Europe since the 1980s. However, there are indications of phenological shifts between 1840 and 1870 (Pettitt's test) and changes in 1930 (highest change-point probability). Finally, we found a greater and more variable temperature sensitivity of change in the UK PPSI with respect to seasonal temperatures $\left(2\right.$ to $\left.15 \mathrm{~d}^{\circ} \mathrm{C}^{-1}\right)$ than in Switzerland $\left(-2.5\right.$ to $\left.-5 \mathrm{~d}^{\circ} \mathrm{C}^{-1}\right)$.
\end{abstract}

KEY WORDS: Plant phenology $\cdot$ Plant phenological spring indices $\cdot$ PPSI $\cdot$ Historical observations · Marsham records $\cdot$ Temperature sensitivity $\cdot$ Change point $\cdot$ Bayes $\cdot$ Pettitt

\section{INTRODUCTION}

Increasing temperatures in recent decades have left their impact on a wide range of environmental parameters, such as snow cover duration or the timing of seasons since the 1970s (Rosenzweig et al. 2007 and references therein). Rosenzweig et al. (2008) showed that changes in biological and physical systems predominantly occur in regions of observed temperature increase, which itself cannot be explained by natural climate variations alone. Change in the measured state of spatially integrated greenness has been documented by satellites at a regional scale (e.g. Studer et al. 2007). These observations are coherent trends in start of season dates and were also detectable in the seasonal cycle of atmospheric $\mathrm{CO}_{2}$ measurements (Keeling et al. 1996), the earlier start of plant growth in high northern latitudes (Myneni et al. 1997) and 
temperature-based start of growing season indicators (Menzel et al. 2003, Linderholm 2006, Schwartz et al. 2006).

Studer et al. $(2005,2007)$ pointed out that a major shift in temperature at the end of the 1980s in Switzerland induced significant trends in hundreds of groundobserved plant phenological and remotely sensed greenness time series. For the same period, Dose \& Menzel (2004) described distinct changes in cherry, lime and snowdrop flowering dates in Germany when they introduced a Bayesian approach to nonparametric function estimation in phenological research. A quantitative estimation of probable change-points, which before had only been described qualitatively, became possible. A detailed analysis for 11 stations in Switzerland (1959 to 1999) revealed that the years of highest probabilities of change-points of leaf unfolding records were also concentrated in the mid-1980s (Schleip et al. 2006). The frequency of maximum change-point probabilities in the 1980s from a comprehensive phenological dataset of $>2600$ long-term observational records across central Europe indicates that most changes in the analysed datasets occurred simultaneously (Schleip et al. 2006).

The plethora of recently published studies documents the strong climate impact on phenological changes at the end of the 20th century (e.g. Menzel \& Fabian 1999, Menzel et al. 2001, Peñuelas et al. 2002, Nordli et al. 2008). Most of these studies are based on phenological observations and temperature measurements starting in the 1950s and 1960s. Extraordinary single season events such as the exceptionally warm European autumn 2006 to spring 2007 (Luterbacher et al. 2007, Yiou et al. 2007, Maignan et al. 2008, Rutishauser et al. 2008) and late spring freeze 2007 in the eastern United States (Gu et al. 2008) are mostly discussed with respect to the same period.

Very few contemporary studies use older and continuous observations (Ahas 1999, Defila \& Clot 2001, Menzel et al. 2005, Rutishauser \& Studer 2007, Aono $\&$ Kazui 2008). However, the period from the 18th to the mid-20th century produced some unique long-term phenological observations and temperature measurements in Switzerland and the UK (see '2.1. Data').

We assess whether synchronised changes in temperature and plant phenological records are detected in centennial time series, and whether recent temperature change induced unprecedented impacts in plant phenology at the end of the 20th century. In the present study we discuss the temporal evolution of a plant phenological start of season indicator, hereafter called plant phenological spring index (PPSI), in Switzerland and in the UK covering the period 1753 to 1958 . We describe plant phenology in comparison with monthly mean temperature changes and discuss the occurrence of common shifts and changes in phenological and temperature long-term time series. Finally, we compare the temperature sensitivity of spring phenology during the transition period from the pre-industrial to early anthropogenic climate state in Europe from 1753 to 1958. In doing so, we can place the impacts of unequivocal temperature change (IPCC 2007) at the end of the 20th century into the perspective of the preceding 2 centuries.

\section{DATA AND METHODS}

\subsection{Data}

In the present study we analysed historical phenological observations and temperature measurements from rural sites in Switzerland and the UK. Plant phenological observations cover the periods 1702 to the present for Switzerland (Rutishauser et al. 2007) and 1736 to 1958 for the UK (Sparks \& Carey 1995). Systematic temperature measurements in Switzerland and in the UK began in 1753 and 1659, respectively. Our study period is defined as the common period for records from 1753 to 1958 when the UK phenology record ends. During the study period the estimated area of arable land in Europe doubled from approximately 0.8 to 1.6 million $\mathrm{km}^{2}$, while forests decreased from 2.5 to 1.5 million $\mathrm{km}^{2}$ (Pongratz et al. 2008). The data are quite uncertain (Ramankutty \& Foley 1999). However, the phenological records used here are at local to regional scales for which no specific information about land-use or human population change is known. Whereas the UK phenological observations were collected $20 \mathrm{~km}$ away from the sea, Swiss sites were located $1000 \mathrm{~km}$ east of the North Atlantic. The altitude of Swiss phenological lowland observation sites range between 300 and $800 \mathrm{~m}$ above sea level (a.s.l.). The UK observations were made close to sea level (20 m a.s.1.).

We use species-specific phenological observations from historical datasets to define a PPSI. For the Swiss PPSI we used data from a spring season reconstruction of Rutishauser et al. (2007) based on 2 flowering (cherry and apple tree) and 1 leaf-out (beech) phases. After 1951, the data were compiled from observations of the Swiss phenological network with 20 to 75 observations per year from up to 20 stations (Defila \& Clot 2001). Before 1950, the Swiss PPSI was statistically reconstructed by a linear modelling approach from 2 to 8 historical observations of the same phenological phases per year (see Pfister 1984, Rutishauser et al. 2007 for a detailed methodological description). The spatial coverage of the Swiss phenological record is a $100 \times 100 \mathrm{~km}$ area of the Swiss Plateau region. 
UK phenological observations were taken from the Marsham dataset (Sparks \& Carey 1995) and updated with previously unpublished data held by the Marsham family that extend the data to 1958 . The Marsham collection contains 27 phenological events for over 20 plant and animal species recorded in Stratton Strawless, Norfolk (Marsham 1789). Here we use the dataset of Sparks \& Carey (1995) also omitting gaps in the dataset that were filled by Margary (1926). The dataset contains numerous missing observations between 1736 and 1745. No observations at all are known for the periods 1811-1834 and 1841-1844. Sparks \& Carey (1995) noted that the data contain extreme outliers which may be the result of processing errors into print. However, no data were corrected or removed. Errata published in the Phenological Reports of the Royal Meteorological Society were included. For the present study, we calculated a PPSI for the UK based on leaf-out of ash, birch, elm and horse chestnut (see '2.2. Methods').

Monthly mean instrumental temperatures were taken from the 2 Swiss stations of Geneva (starting 1753) and Basel (starting 1755) (Schüepp 1961, Begert et al. 2005, Meteo Swiss 2008) and were transformed into a mean Swiss temperature series. For the UK, Central England temperature (Manley 1974, Parker et al. 1992, Met Office 2008) data representative of the English Midlands were used. Both temperature datasets are homogenized and represent a regional average close to the locations of the 2 phenological records. Monthly averages are aggregated to seasonal spring (March-May), winter (December-February), autumn (September-November) and summer (July-August) averages.

\subsection{Methods}

This section describes the methods applied for generating 2 long-term phenological time series and describing the phenological and temperature series including shifts and change-points. Finally, we present 2 methods for describing temperature impact on phenology. All time series were tested for normal distribution (data not shown).

The Swiss and UK PPSIs are defined as the weighted mean of all available observations applying the 2-way crossed mixed linear model (MLM) approach used by Schaber \& Badeck (2002). For regional averages, Schaber \& Badeck (2002) fitted a linear model ANOVA and maximum likelihood estimations accounting for random station effects (i.e. local climate and environmental specificities) and fixed year effects (i.e. systematic differences between observation sites). We used the R 'pheno' package (Schaber 2003). For Swiss phenological station data we followed the method of Schaber \& Badeck (2002), and adapted it to the UK phenological observations. As the selected phases stem from the same vicinity, there are no random station effects. However, we assumed that the effects between phases are random (i.e. species-specific spring development) and that the year effects remain fixed (i.e. systematic differences between species).

\subsection{Time series description}

For decadal time series descriptions we applied a $20 \mathrm{yr}$ smooth minimum roughness constraint calculated according to Mann $(2004,2008)$. We then looked for years with shifts in the phenological and temperature time series applying Pettitt's test (Pettitt 1979, Demarée 1990, Nordli 1996). When a series consists of 2 sub-series having different distributions, the series is said to have a shift, which corresponds to the last element, $k_{1}$ in the first series (Sneyers 1995). The test statistic $X_{k}$ is defined by:

$$
X_{k}=2 R_{k}-k(n+1)
$$

and

$$
R_{k}=\sum_{i=1}^{k} r_{i}
$$

where $r_{i}$ is the rank of the $i$ th element in the complete series of $n$ elements. If shifts are absent in the series, i.e. under the null hypothesis of randomness, the expectation value of $X_{k}$ is 0 . An extreme value, $X_{\mathrm{E}}$, is significant for an abrupt decreasing or increasing shift if:

$$
\left|X_{\mathrm{E}}\right| \geq \sqrt{-\frac{1}{6}\left(n^{3}+n^{2}\right) \ln \frac{\alpha}{m}}
$$

where $m=1$ for a 1 -sided test or 2 for a 2-sided test, and $\alpha$ is the chosen level of significance.

In addition to the detection of shifts (Pettitt's test) we used a Bayesian model comparison analysis to detect possible change-points, where 2 distinct trends meet, as opposed to a constant or linear trend evolution of the time series (analogous to Schleip et al. 2008b, based on Dose \& Menzel 2004). In this approach, Model I (constant model) represents the hypothesis of no change at all with an associated zero rate of change. Model II (linear model) assumes a time-linear change with an associated constant rate of change. Model III (changepoint model) allows for a time-varying trend over the record period. The change-point model is based on a triangular function, hence 2 linear segments, which match at a particular change-point. A Bayesian marginalization rule was employed to eliminate the changepoint variable from the model function. The result of this marginalization is a superposition of all possible 
triangular functions weighting each year by its respective change-point probability (see Schleip et al. 2008b for details). Using the Bayesian approach we studied: (1) the probabilities of Models I to III, (2) years with maximum change-point probability in the change-point model and (3) the rates of change of the constant and linear model (Dose \& Menzel 2004, Schleip et al. 2008b).

\subsection{Temperature impact and coherence}

In addition to Pearson correlation analysis between the phenological series and monthly mean temperatures, we used a Bayesian correlation approach for the analysis of the coherence of temperature and phenological time series (Dose \& Menzel 2006, Schleip et al. 2008b and references therein). We related the temporal distribution of the change-point of phenological and temperature series to each other and tested the hypothesis whether 2 time series evolve independently or exhibit coherence. The ratio of the probabilities $\mathrm{p}$ (coherent) $/ \mathrm{p}$ (independent), named the coherence factor, describes dependent evolution. In addition, we estimated temperature weights of each monthly mean
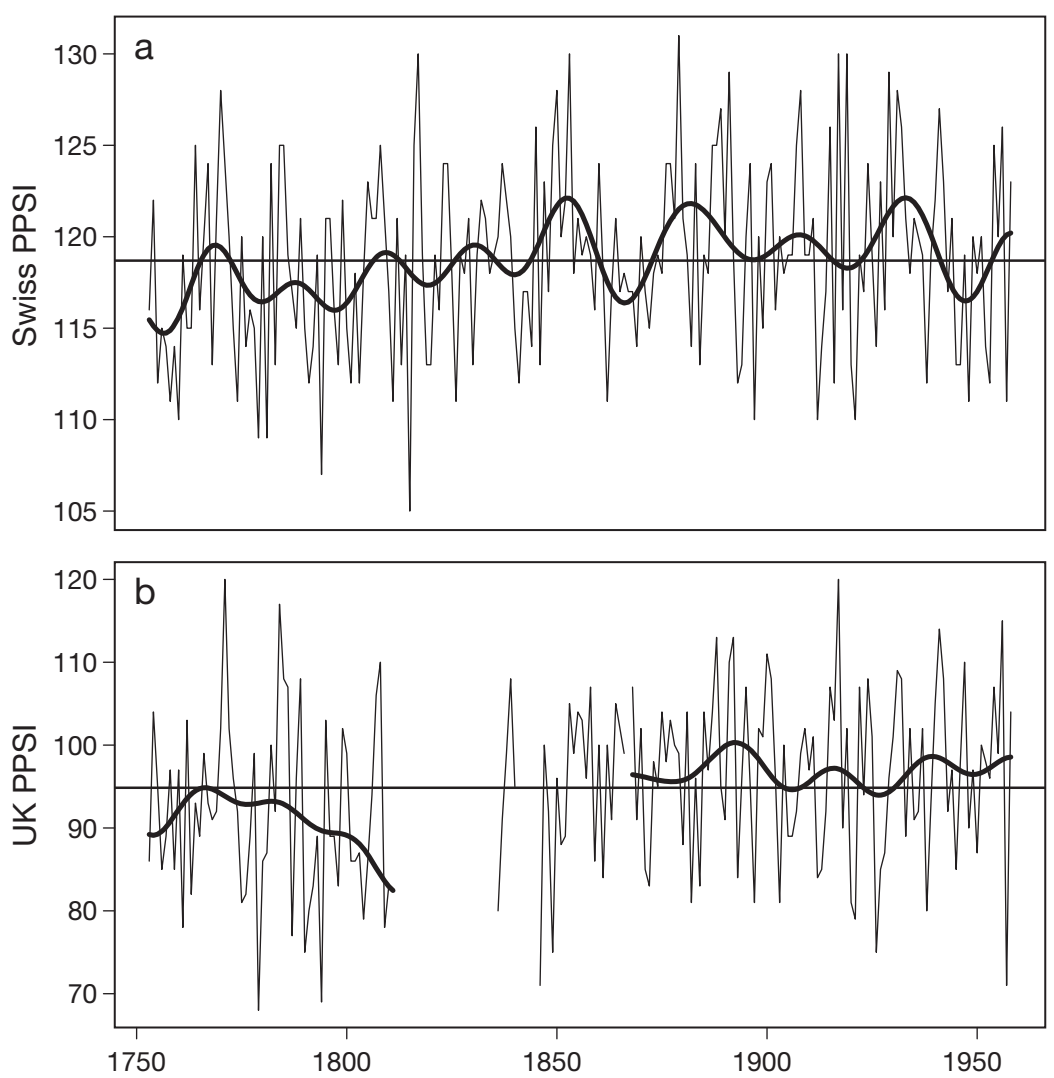

Fig. 1. Plant phenological spring index (PPSI) dates (in days after December 31) for (a) Switzerland and (b) the UK for the period 1753-1958. Bold lines show 20 yr filtered low-frequency variability with a minimum slope and minimum norm constraint for (a) and (b), respectively, according to Mann $(2004,2008)$. Note different scale of $y$-axes temperature preceding the phenological event by implementing a simulated annealing algorithm that maximizes the coherence between temperature and phenology time series (Dose \& Menzel 2006, Schleip et al. 2008a).

Finally, the description of changing temperature sensitivity of phenology over time was described by a moving sensitivity approach (Rutishauser et al. 2008). For each 30 yr period temperature sensitivity was calculated as the slope coefficient of a linear regression model with phenology as the dependent variable and seasonal and monthly mean temperature as the independent variable. For each regression model we also estimated the $95 \%$ confidence interval (CI) for temperature sensitivity.

\section{RESULTS}

\subsection{Phenological and temperature changes}

Fig. 1 presents the PPSI in Switzerland and the UK for the period 1753 to 1958 . The more continental Swiss records had a mean PPSI (29 April, Day 119) 24 d later the UK mean (5 April, Day 95) (Table 1). The Swiss record also has a lower interannual variability (SD) of $5 \mathrm{~d}$ in comparison to $10 \mathrm{~d}$ in the UK. The earliest phenological observations are on 15 April (1815; Day 105) and 9 March (1779; Day 68), the latest on 11 May (1879; Day 131) and 30 April (1917; Day 120) in Switzerland and the UK, respectively.

At interannual time scales the Swiss and UK PPSIs are significantly correlated ( $\mathrm{r}=0.56, \mathrm{p}<0.001)$. At decadal time scales the correlation is negative and not significant $(r=-0.12, p=0.257)$. Negative correlations between the indices and preceding monthly mean temperatures indicate earlier PPSI values after warmer late-winter and spring temperatures (Table 2).

Seasonal temperature records are presented in Fig. 2 ordered from the most important season (spring, top row), the preceding winter (second row) to autumn (third row) and summer of the previous year (bottom row). All seasons and both regions show a transition from negative to positive temperature anomalies from the 19th to the 20th century. The decade 1945-1954 contained the largest number of very warm 
Table 1. Summary of phenological and temperature series: mean linear rate of change and model probabilities for change-point, linear and constant models as estimated from a Bayesian model comparison. PPSI: plant phenological spring indices; CH: Switzerland. Spring: March-May; winter: December-February; autumn: September-November; summer: June-

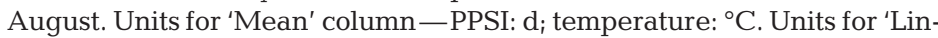
ear rate of change' column-PPSI: $\mathrm{d}_{\text {decade }}{ }^{-1}$; temperature: ${ }^{\circ} \mathrm{C}$ decade $^{-1}$

\begin{tabular}{|c|c|c|c|c|c|c|}
\hline & & \multirow[t]{2}{*}{ Mean } & \multirow{2}{*}{$\begin{array}{l}\text { Linear rate } \\
\text { of change }\end{array}$} & \multicolumn{3}{|c|}{ Model probabilities (\%) } \\
\hline & & & & Change-point & Linear & Constant \\
\hline \multicolumn{7}{|c|}{ PPSI } \\
\hline $\mathrm{CH}$ & & 119 & 0.1 & 47 & 45 & 8 \\
\hline UK & & 95 & 0.3 & 31 & 64 & 5 \\
\hline \multicolumn{7}{|c|}{ Temperature } \\
\hline \multirow[t]{4}{*}{$\mathrm{CH}$} & Spring & 8.8 & 0.02 & 99.5 & 0.3 & 0.2 \\
\hline & Winter & 0.6 & 0.08 & 91 & 2.5 & 6.5 \\
\hline & Autumn & 9.1 & 0.04 & 88 & 12 & 0 \\
\hline & Summer & 17.5 & -0.01 & 42 & 58 & 0 \\
\hline & Spring & 8.1 & 0.01 & 53 & 22 & 25 \\
\hline & Winter & 3.7 & 0.05 & 48 & 15.5 & 36.5 \\
\hline & Autumn & 9.5 & 0.03 & 83 & 16.5 & 0.5 \\
\hline & Summer & 15.2 & -0.01 & 34 & 66 & 0 \\
\hline
\end{tabular}

springs leading to a positive decadal anomaly of $2^{\circ} \mathrm{C}$ in Switzerland. The other decades varied between $\pm 0.5^{\circ} \mathrm{C}$ with respect to the $1753-1958$ mean. For the UK, the coolest decadal spring temperatures were measured in the 1880s and the warmest in the 1940s. In Switzerland, cold winter decades were measured with up to a $-1^{\circ} \mathrm{C}$ mean anomaly in the 1760 s, 1820 s and 1860s. Within the period 1910-1930 and the 1940s, many warm years have been experienced. The UK record showed a similar distribution of cold and warm decadal anomalies.

\subsection{Shifts and changes}

Phenological and temperature series were analyzed by Pettitt's test for shifts (Fig. 3). A statistically significant shift towards a later start of the season could be found in the UK phenological record with 1852 as the most likely year. Winter and autumn temperatures also showed significant shifts, namely towards warmer temperatures. The timing of the shift for winter tem-

Table 2. Pearson correlations between plant phenological spring indices (PPSI) and mean temperatures of preceding months, winter and spring during the period 1753-1958. Bold: significant at $p=0.05$. CH: Switzerland. Spring: MarchMay; winter: December-February

\begin{tabular}{|lrrrrrrr|}
\hline & Jan & Feb & Mar & Apr & May & Winter & Spring \\
\hline CH & 0.01 & $\mathbf{- 0 . 2 8}$ & $\mathbf{- 0 . 4 3}$ & $\mathbf{- 0 . 5 7}$ & -0.14 & -0.12 & $\mathbf{- 0 . 6 4}$ \\
UK & -0.18 & $\mathbf{- 0 . 5 5}$ & $\mathbf{- 0 . 6 6}$ & -0.25 & 0.02 & $\mathbf{- 0 . 3 7}$ & $\mathbf{- 0 . 5 0}$ \\
\hline
\end{tabular}

perature was 1897 for Switzerland and 1842 for the UK. For autumn temperature, shifts were most probable in 1922 (Switzerland) and 1896 (UK).

Table 1 presents the probabilities of the Bayesian model comparisons. The Swiss PPSI is equally well described by a linear or onechange-point model with 47 and $45 \%$ probability. In the UK PPSI, a linear model best described interannual variability with a probability of $64 \%$ in comparison with $31 \%$ for a model with a major change-point. The summer temperature series were also best described by a linear rate of change as calculated by the Bayesian model comparison analysis (Table 1). Probabilities were 58 and $66 \%$ for Switzerland and the UK, respectively. A change-point model best describes all other seasons except for UK winter temperatures that indicated quite a high probability of no change. Finally, Swiss spring, winter and autumn temperature records favour the onechange-point model whereas the model selection for the UK was much less clear.

Fig. 4 depicts the probabilities of a change-point in the phenological and temperature records for each year in the period 1753-1958. The Swiss PPSI had the highest probability in $1932(0.95 \%)$, and there was a secondary peak in $1765(0.73 \%)$. The UK phenological index showed 2 very distinct peaks at the beginning and at the end of the record. However, there was a strong indication that the one-change-model described the temporal evolution of the time series with a probability of $31 \%$ (Table 1 ). Seasonal temperatures for spring, winter and autumn with a high changepoint model probability (Fig. 4b,c, Table 1) revealed clear peaks in the timing of change in Switzerland and the UK.

The more continental region in Switzerland showed the clearest change in winter temperatures in 1915 with secondary peaks in 1817 and 1845. Spring temperatures indicated the highest probabilities for a change in 1854 with 2 secondary peaks in 1890 and 1900. Swiss autumn temperatures showed the major change for 1916 very similar, but with lower probability, to the winter temperatures. Secondary peaks were stronger in 1851 and 1890. Change-point probabilities in UK temperature records were more similar in all seasons. For spring, winter and autumn the highest probability for a change in the time series were in 1906, 1917 and 1920, respectively, with increasing probability. Secondary peaks were only found after 1880. Summer temperatures were equally well or better described by a linear trend model (Table 1). 

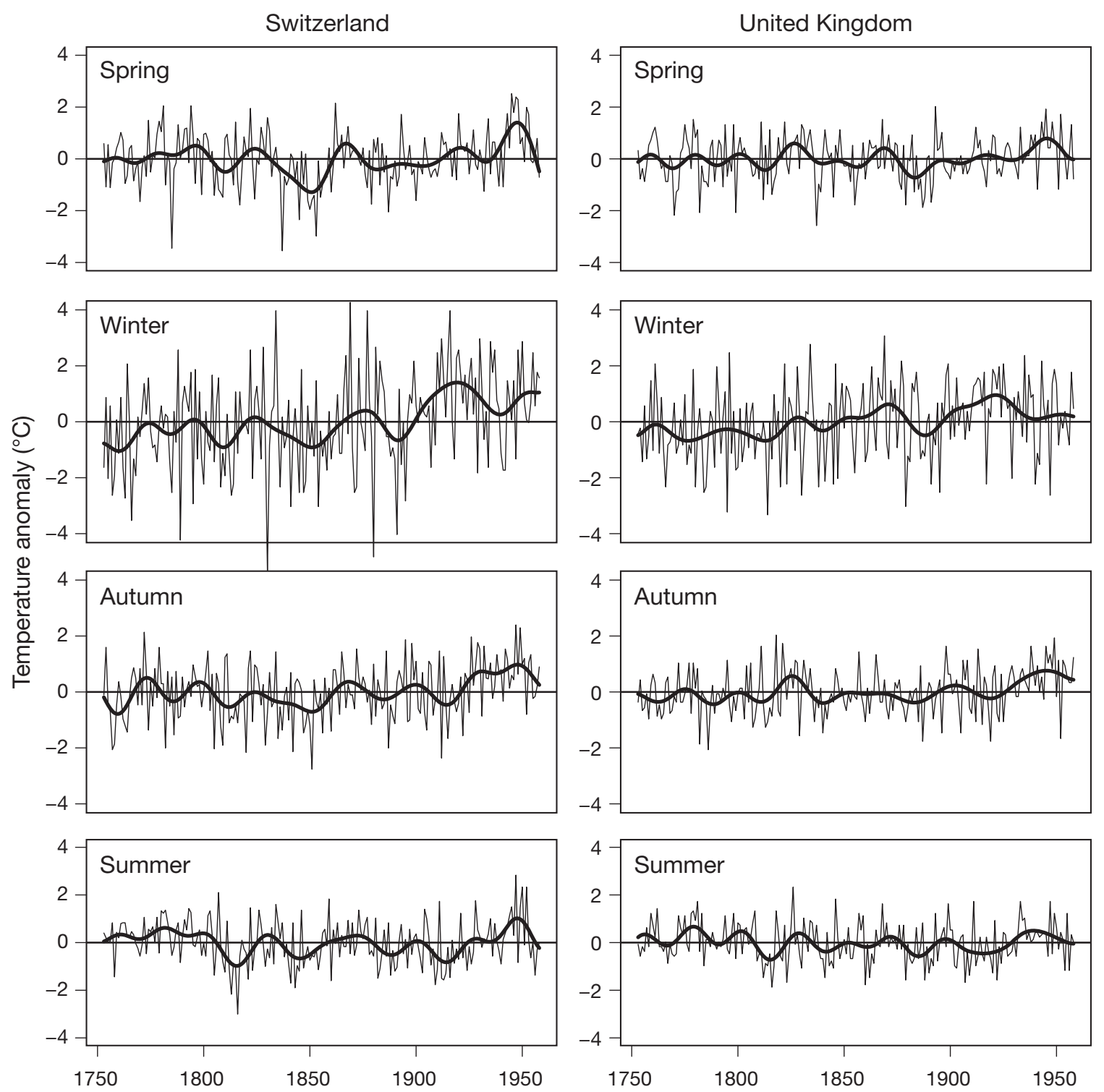

Fig. 2. Swiss and Central England seasonal mean temperature anomalies for the period 1753-1958 with respect to the long-term mean. Bold lines indicate $20 \mathrm{yr}$ smoothing according to Mann $(2004,2008)$. Spring and winter temperatures are of the current year; autumn and summer temperatures are of the previous year

\subsection{Temperature impact and sensitivity}

Coherence and assigned temperature weights between phenological records and seasonal mean temperatures was low. A high coherence was only seen for the Swiss series (factor $=1.11$ ). Assigned temperature weights were strongest for spring and the preceding autumn seasonal temperatures. For the UK, coherence was low (factor $=0.44$ ) and temperature weights revealed an impact of current spring and preceding summer temperatures.

Table 2 presents correlation coefficients between the phenological and preceding monthly mean temperatures. Spring season temperatures were more strongly correlated with the Swiss PPSI, whereas winter temperatures also influenced the start of the season in the UK.

Temporal changes in temperature sensitivity were systematically different in Switzerland and the UK (Figs. $5 \& 6$ ). The response to a $1^{\circ} \mathrm{C}$ increase in spring (March-May) temperature during a 30 yr shifting time window was -2.5 to $-5 \mathrm{~d}$ in Switzerland and -2.5 to $-15 \mathrm{~d}$ in the UK (Fig. 5). Uncertainties were generally higher in the UK than in Switzerland. The response to winter (December-February) temperature was lower at +1 to $-2 \mathrm{~d}$ and -1 to $-5.5 \mathrm{~d}$ in Switzerland and the UK, respectively. The Swiss record does not differ significantly from zero, and the UK record only in the 
early and late part of the record. There were neither significant changes nor systematic trends found in the sensitivity records.

Finally, Fig. 6 presents the changing phenological response of the 2 phenological indices to monthly mean temperatures from January to April. April was omitted for the UK because the mean date was 5 April. February mean temperatures significantly influenced the UK PPSI throughout the period analyzed, whereas significant sensitivities in Switzerland were only detectable in the 20th century data. Sensitivity to March temperatures was the highest of all in the UK with changes of -4 to $-7 \mathrm{~d}^{\circ} \mathrm{C}^{-1}$ temperature increase. Swiss spring phenology only changed -1 to $-3 \mathrm{~d}^{\circ} \mathrm{C}^{-1}$ and non-significantly in the late 1800s. Finally, April temperatures significantly influenced Swiss phenology.

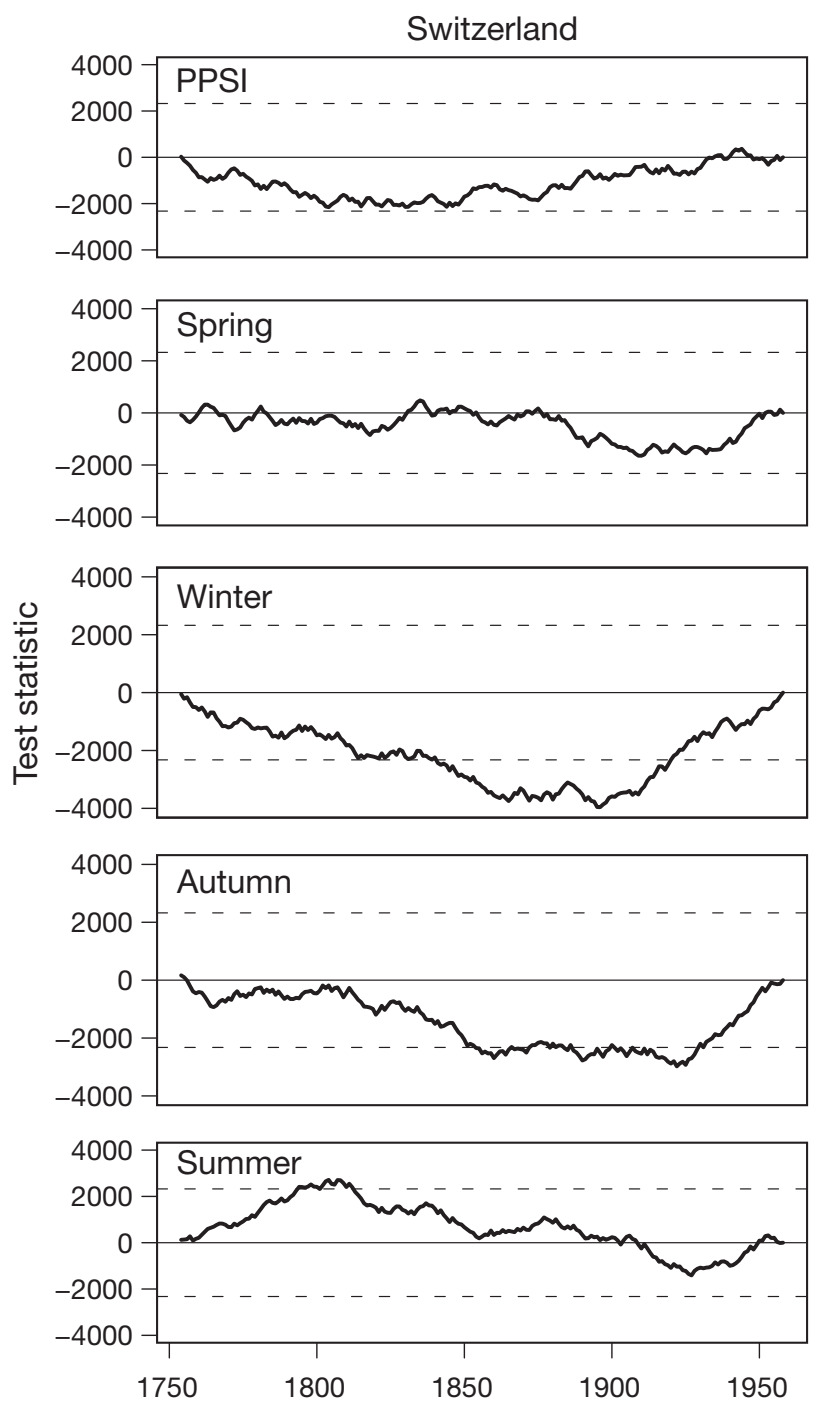

\section{DISCUSSION}

The present study analysed climate impacts on plant phenology before 1960 since the UK record from the Marsham family was terminated in 1958 (Sparks \& Lines 2008). We took advantage of the unique situation of 2 European regions with high quality temperature measurements starting in the middle of the 1700 s and unique plant phenological records.

\subsection{Synchronous change of phenology and temperature}

Plant phenological variability over the entire 17531958 period was generally higher in the UK than in the Swiss record. This contradicts the assumption that
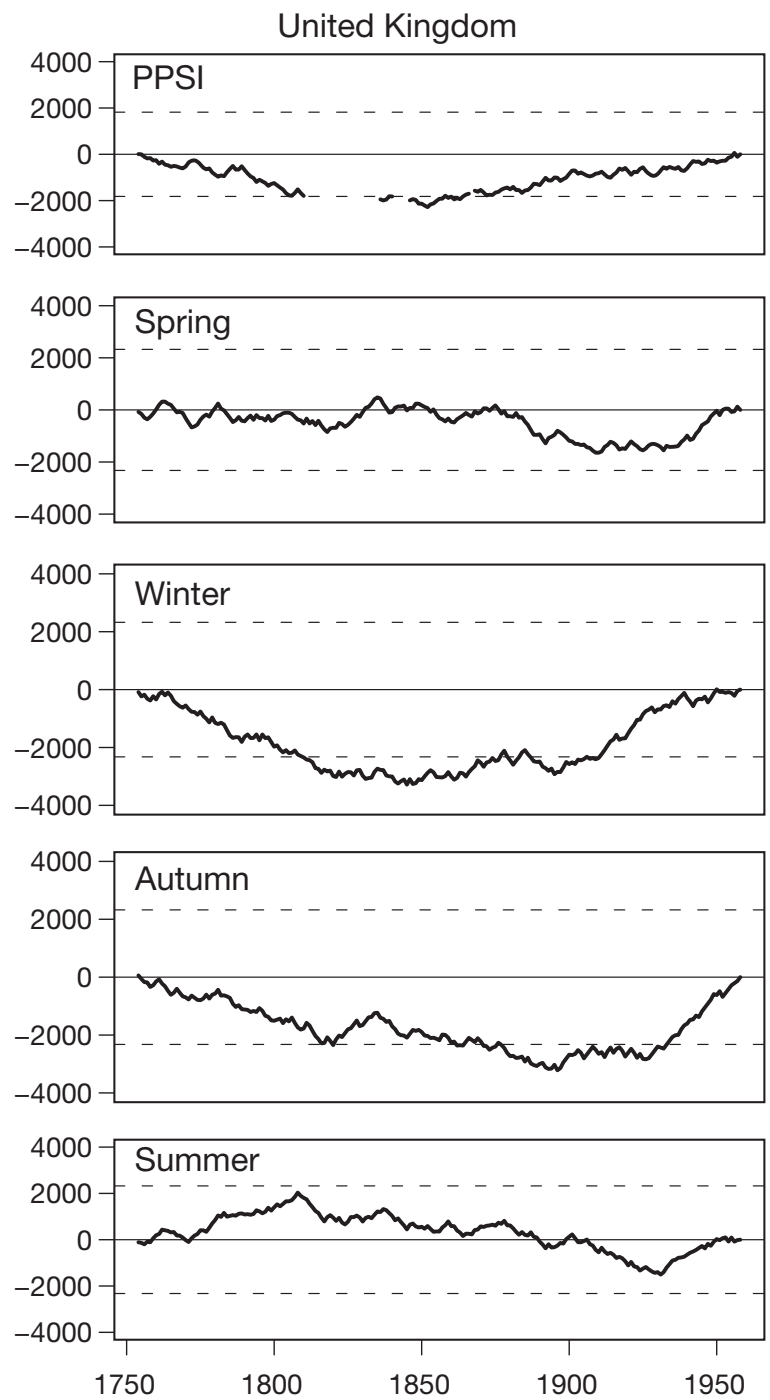

Fig. 3. Probabilities of shifts in phenological and seasonal temperature series according to Pettit's test. The plotted line shows the test statistic $X_{k}$ (see '2.3. Time series description') for each year. Dotted lines indicate $95 \%$ CI 

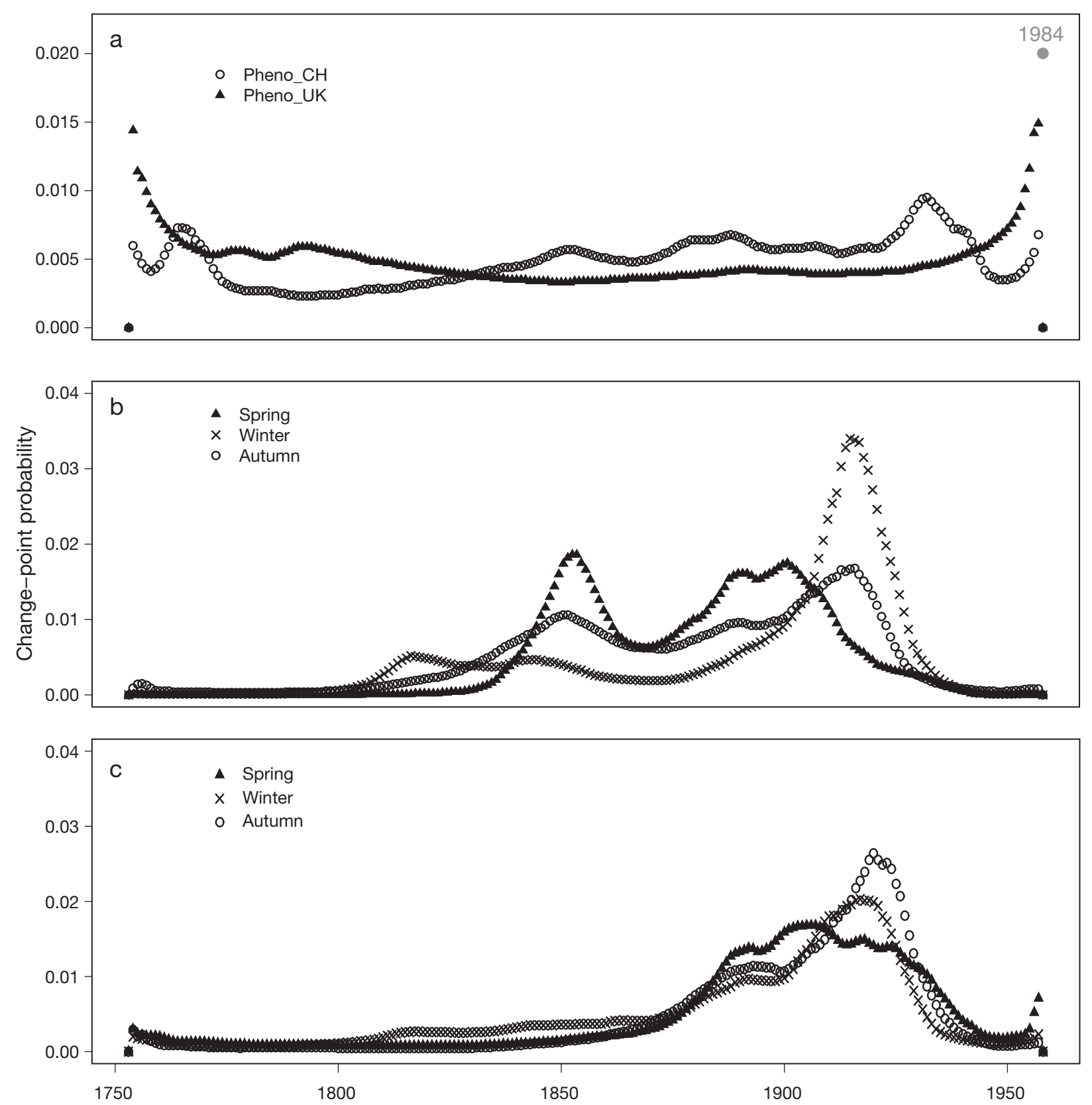

Fig. 4. Change-point probabilities for (a) the phenological series of Switzerland ( $\mathrm{CH}$ ) and the UK, (b) seasonal Swiss and (c) UK temperatures 1753-1958. Note different scales for y-axes. Grey dot in (a) indicates the change-point probability for the Swiss PPSI in the period 1753-2006 (from Schleip et al. 2008b)

more continental sites have higher variability in plant phenological dates due to a more variable climate. Seasonal mean temperatures, however, revealed a greater variability at the more continental Swiss site than in the UK. One possible explanation concerns the characteristics of the phenological series analysed. Whereas the UK record was observed at a single location with a site-specific microclimate, the Swiss PPSI represents a synoptic-scale spatial mean date of the Swiss Plateau region of $10 \mathrm{~s}$ of $\mathrm{km}$ (Siljamo et al.
2008) - local climatic effects are dampened. Furthermore, the Swiss record includes flowering and leaf-out dates in contrast to the UK PPSI that is based solely on 4 leaf-out phases. Finally, the reconstruction method used to create the Swiss PPSI is based on linear regression methods that are sensitive to present or absent extreme values in the calibration period of the transfer function (Rutishauser et al. 2007).

The Bayesian coherence approach also supports spring temperature impacts on plant phenology at both 


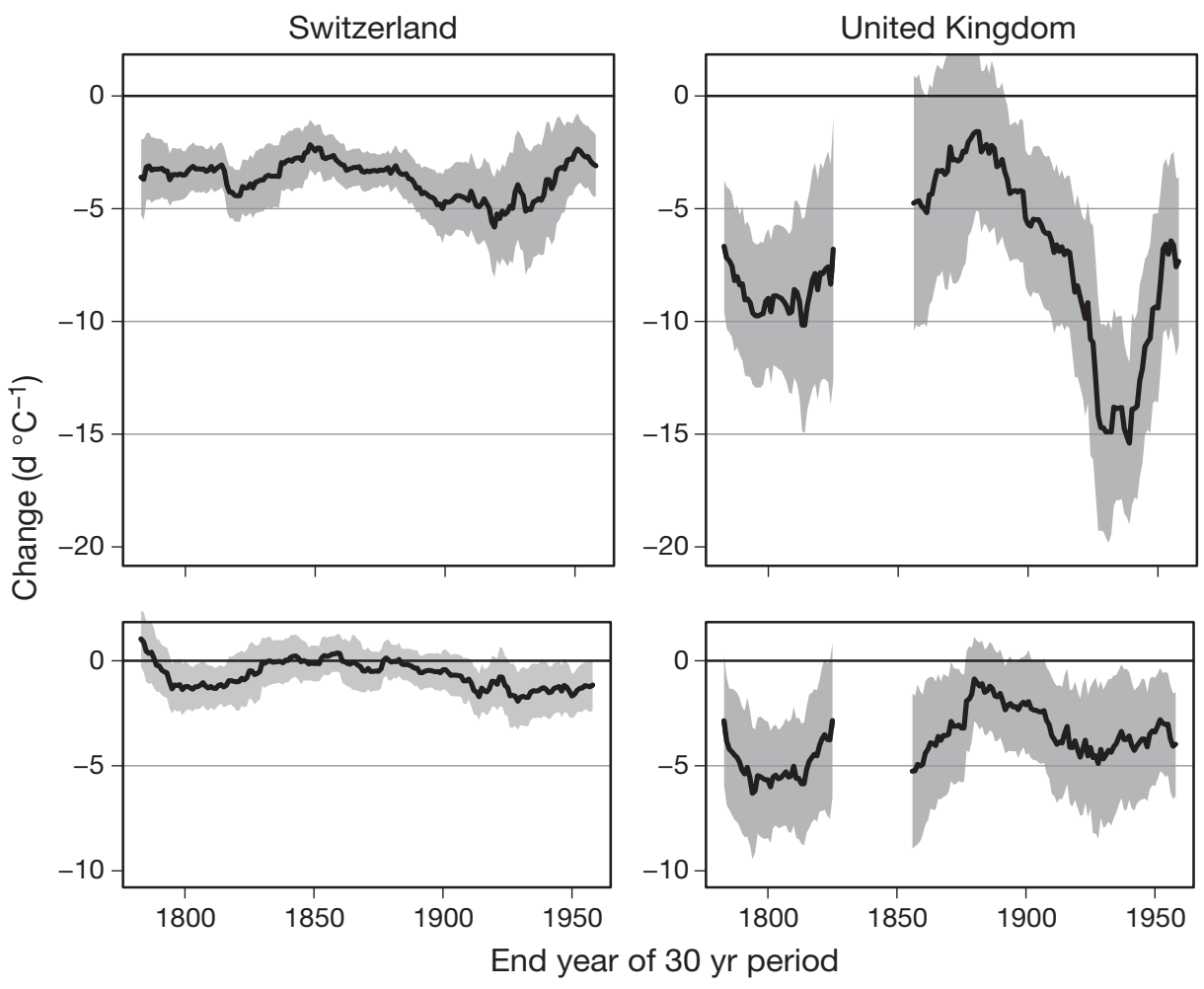

Fig. 5. Moving temperature sensitivity between Swiss and UK plant phenological spring indices (PPSI) and spring (March-May, top) and winter (December-February, bottom) seasonal mean temperatures. Sensitivities are the regression coefficient from a $30 \mathrm{yr}$ window with at least 15 pairs of observations, and show the number of days changed per ${ }^{\circ} \mathrm{C}$. Shaded areas indicate $95 \%$ CI of the linear regression coefficient
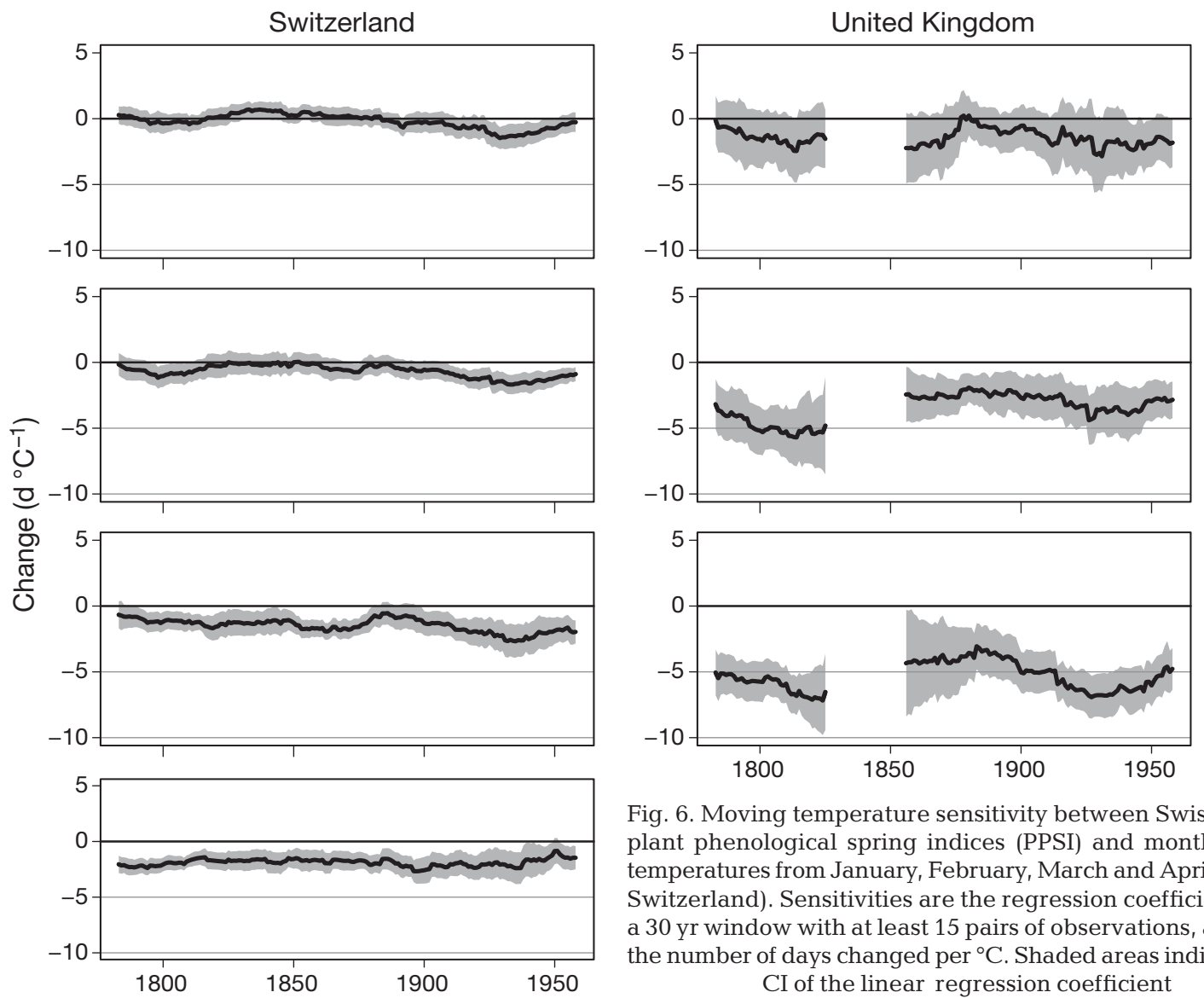

Fig. 6. Moving temperature sensitivity between Swiss and UK plant phenological spring indices (PPSI) and monthly mean temperatures from January, February, March and April (only for Switzerland). Sensitivities are the regression coefficients from a $30 \mathrm{yr}$ window with at least 15 pairs of observations, and show the number of days changed per ${ }^{\circ} \mathrm{C}$. Shaded areas indicate $95 \%$ $\mathrm{CI}$ of the linear regression coefficient 
locations. However, it is rather low with coherence factors of 1.11 (Switzerland) and 0.44 (UK). Autumn (Switzerland) and summer (UK) temperatures of the previous year are assigned a statistical influence on spring phenology of the current year. Temperature impacts of the previous summer were also documented by Doi et al. (2008), who associated warmer and drier summers with earlier flowering dates of several Prunus cultivars.

\subsection{Abrupt changes in spring season}

The linear regression approach for trend analyes as applied in many phenological investigations does not fully account for abrupt changes, only for a general development, in the onset of spring. Long-term phenological series record environmental impacts over a period that potentially experiences more than one shift. As a consequence, the Bayesian model comparison and especially the change-point model should account for the possibility of identifying major nonlinear changes. Schleip et al. (2008b) found the highest probability for a change-point in 3 long-term phenological records from France and Switzerland at the end of the 20th century. Analysing the Swiss PPSI for the period 1753 to 2006, a dominating change-point was found in 1984 with a $2 \%$ probability (Fig. 4a). This probability is twice as high compared to the findings of the present study $(<1 \%)$. These results support the findings of unprecedented changes in phenological records (Dose \& Menzel 2004, Studer et al. 2005). Dose \& Menzel (2004) detected change-point probabilities of 5 to $10 \%$ in 3 phenological records from Geisenheim, Germany, for 1896-2002. Even though not fully discussed, Schleip et al. (2008b, their Fig. 2d-g) also found other periods in the change-point probability distribution that indicated secondary peaks and periods of change. Namely, in the present study, the Swiss PPSI record shows potential change-points between 1850 and 1950 with weak peaks around 1890 and 1935, as already indicated by Schleip et al. (2008b). We explicitly used the same Bayesian model comparison setup as Schleip et al. (2008b), as the change-point distributions also identify possible minor changes in long-term time series. In the present study ending in 1958, we focused especially on secondary major and minor change-points in the phenological time series. The presence of minor secondary changes in long-term series indicates changes in phenology and temperature. The lack of a clear one-point-change in phenology supports the hypothesis that recent changes are unprecedented.

Pettitt's test has been used for break point detection in European temperature time series that start around the mid-19th century. The testing resulted in the detec- tion of a warming with shifts in the 1910s or 1920s, called the early 20th century warming (Demarée 1990, Nordli 1996, Hanssen-Bauer et al. 1996). This warming also seems to have occurred in the Swiss autumn temperature series (1922, Fig. 4). In the UK autumn series, the most likely change occurs in 1896, but there is a secondary peak in 1926. For the other series, the early 20th century warming is not detected, as the changes occurred in the 19th century. The spread of the test statistics (Fig. 4) indicates that there is no clearly defined shift in the series. Rather, there are decades with a higher probability of shifts. For the spring temperature series, no significant shifts were detected.

Changes in temperature sensitivity are much more variable when calculated from seasonal averages rather than monthly mean temperatures (Figs. 5 \& 6). UK PPSI showed exceptionally strong temperature sensitivity at the beginning of the 20th century with sensitivity up to $15 \mathrm{~d}{ }^{\circ} \mathrm{C}^{-1}$. The Swiss series also showed the strongest sensitivity during this period but only up to $5 \mathrm{~d}^{\circ} \mathrm{C}^{-1}$. The higher uncertainty in regression coefficients in the UK can be attributed on the one hand to differences in data sources: the UK single site observations contain local pecularities that induce extreme values together with the fact that observations were made by a single family. On the other hand, the moving sensitivity approach focuses on the shift of a $30 \mathrm{yr}$ window along the time series. We hypothesize that extreme single events have a high impact on temperature sensitivity. Following Sparks et al. (2000), we need to assume that very early and very late years influence sensitivity as calculated by regression models. Finally, we suggest including changes in the number of frost days and timing of last frost in future analyses. This is most important in periods with a high frequency of extraordinary warm years such as the 1940s or the present time.

\section{CONCLUSIONS}

The present study focused on the comparison of unique plant phenological observation and temperature measurements from 2 localities in Europe from 1753 to 1958 . We found distinct differences in PPSI based on specific phenological phases. The record from Switzerland shows lower interannual variability than the UK record, as well as lower changes in temperature sensitivity over time when a moving window linear regression approach was applied. This is in contradiction to higher seasonal temperature variability for the more continental Swiss locality.

We found no unequivocal shift or synchronous change-point in phenological and temperature time series before 1958. Shifts in the UK phenological series 
are indicated for 1852 with rather high timing uncertainty, whereas no statistically significant shift was reported for Switzerland. The timing of change-points describing a change in the linear rate of change is reported for the period before 1800 and after 1900. Seasonal temperatures, except for summer, show change-points after 1880. The accumulation of shifts and change-points in many phenological time series for the end of the 1980s (Dose \& Menzel 2004, Studer et al. 2005) was not found for the Swiss and UK phenological and temperature records prior to 1958. Thus we support the hypothesis that recent temperature change has likely induced unprecedented impacts on plant phenological time series with respect to the 1753 to 1958 period. Moreover, we find that peaks and shifts in phenological and temperature data across the entire 1753-1958 period are ambigous and not synchronised, as opposed to those found at the end of the 20th century.

Future research should include process-oriented explanations including atmospheric circulation patterns. Atmospheric flow is not only explanatory for temperature and precipitation variability but also strongly steers short-term extreme meteorological events such as heat waves, droughts and frost spells. Furthermore, the role of an oceanic longer-term memory effect that influences atmosperic circulation itself should be included in phenological impact studies, specifically in long-term studies. As more daily temperature measurements become rescued and digitised from archives, the possibilities for more detailed modelling of the past centuries based on daily data will increase. Together with the rescue of meteorological data, we stress the importance of historical phenological data from different regions in Europe. They provide crucial evidence for a spatial interpretation of past climate-plant interactions. The ever-growing number of observations will further help to verify and understand process-based modelling studies.

Acknowledgements. This work was initiated by a Short Term Scientific Mission travel grant from the ESF Cost Action 725 'Establishing a European Phenological Data Platform for Climatological Applications'. T.R. acknowledges support by the Swiss National Science Fundation through its National Centre of Competence in Research on Climate (NCCR). We thank the anonymous reviewers for their comments on an early version of the manuscript.

\section{LITERATURE CITED}

Ahas R (1999) Long-term phyto-, ornitho- and ichthyophenological time-series analyses in Estonia. Int J Biometeorol 42:119-123

> Aono Y, Kazui K (2008) Phenological data series of cherry tree flowering in Kyoto, Japan, and its application to reconstruction of springtime temperatures since the 9th century. Int J Climatol 28:905-914
Begert M, Schlegel T, Kirchhofer W (2005) Homogeneous temperature and precipitation series of Switzerland from 1864 to 2000. Int J Climatol 25:65-80

> Defila C, Clot B (2001) Phytophenological trends in Switzerland. Int J Biometeorol 45:203-207

Demarée GR (1990) Did an abrupt global climate warming occur in 1920? R Meteorol Inst, Brussels. Publ Série A:124

Doi H, Gordo O, Katano I (2008) Heterogeneous intra-annual climatic changes drive different phenological responses at two trophic levels. Clim Res 36:181-190

> Dose V, Menzel A (2004) Bayesian analysis of climate change impacts in phenology. Glob Change Biol 10:259-272

$>$ Dose V, Menzel A (2006) Bayesian correlation between temperature and blossom onset data. Glob Change Biol 12: 1451-1459

> Gu L, Hanson PJ, Mac Post W, Kaiser DP and others (2008) The 2007 Eastern US spring freeze: Increased cold damage in a warming world? Bioscience 58:253-262

Hanssen-Bauer I, Nordli Ø, Førland EJ (1996) Principal component analysis of the NACD temperature series. Norwegian Meteorological Institute (DNMI), Report No. 1/96 klima, Oslo

IPCC (2007) Climate Change 2007: the physical science basis. Contribution of Working Group I to the Fourth Assessment Report of the Intergovernmental Panel on Climate Change, Cambridge University Press, Cambridge

Keeling CD, Chin JFS, Whorf TP (1996) Increased activity of northern vegetation inferred from atmospheric $\mathrm{CO}_{2}$ measurements. Nature 382:146-149

> Linderholm HW (2006) Growing season changes in the last century. Agric For Meteorol 137:1-14

> Luterbacher J, Liniger MA, Menzel A, Estrella N and others (2007) Exceptional European warmth of autumn 2006 and winter 2007: historical context, the underlying dynamics, and its phenological impacts. Geophys Res Lett 34:L12704, doi:10.1029/2007GL029951

Maignan F, Bréon F, Vermote E, Ciais P, Viovy N (2008) Mild winter and spring 2007 over western Europe led to a widespread early vegetation onset. Geophys Res Lett 35: L02404, doi:10.1029/2007GL032472

> Manley G (1974) Central England temperatures: monthly means 1659-1973. Q J R Meteorol Soc 100:389-405

> Mann ME (2004) On smoothing potentially non-stationary climate time series. Geophys Res Lett 31:L07214, doi:10. 1029/2004GL019569

Mann ME (2008) Smoothing of climate time series revisited. Geophys Res Lett 35, L16708, doi: 10.1029/2008GL034716

Margary I (1926) The Marsham phenological record in Norfolk, 1736-1925. Q J R Meteorol Soc 52:27-54

Marsham RA (1789) Indications of spring. Philos Trans R Soc Lond 79:154-156

> Menzel A, Fabian P (1999) Growing season extended in Europe. Nature 397:659

> Menzel A, Estrella N, Fabian P (2001) Spatial and temporal variability of the phenological seasons in Germany from 1951 to 1996. Glob Change Biol 7:657-666

> Menzel A, Jakobi G, Ahas R, Scheifinger H, Estrella N (2003) Variations of the climatological growing season (19512000) in Germany compared with other countries. Int J Climatol 23:793-812

> Menzel A, Estrella N, Testka A (2005) Temperature response rates from long-term phenological records. Clim Res 30: $21-28$

Meteo Swiss (2008) Swiss mean temperatures. Available at www.meteoschweiz.admin.ch/web/en/climate/climate_ today/homogeneous_data.html

Met Office (2008) Met Office Hadley Centre Central England 
temperature data. Met Office Hadley Centre for Climate Change, available at http://hadobs.metoffice.com/hadcet/ data/download.html

Myneni RB, Keeling CD, Tucker CJ, Asrar G, Nemani RR (1997) Increased plant growth in the northern high latitudes from 1981 to 1991. Nature 386:698-702

Nordli $\varnothing$ (1996) Analysis of long Norwegian time series of temperature. Prace Geograficzne 102:99-105

Nordli Ø, Wielgolaski FE, Bakken AK, Hjeltnes SH, Måge F, Sivle A, Skre O (in press) (2008) Regional trends for bud burst and flowering of woody plants in Norway as related to climate change. Int $\mathrm{J}$ Biometeorol 52:625-639 doi: 10.1007/s00484-008-0156-5

Parker DE, Legg TP, Folland CK (1992) A new daily central England temperature series. Int J Climatol 12:317-342

> Peñuelas J, Filella I, Comas P (2002) Changed plant and animal life cycles from 1952 to 2000 in the Mediterranean region. Glob Change Biol 8:531-544

Pettitt AN (1979) A non-parametric approach to the changepoint problem. Appl Stat 28:126-135

Pfister C (1984) Klimageschichte der Schweiz 1525-1860. Paul Haupt, Bern

Pongratz J, Reick C, Raddatz T, Claussen M (2008) A reconstruction of global agricultural areas and land cover for the last millennium. Global Biogeochem Cycles 22:GB3018. doi:10.1029/2007GB003153

Ramankutty N, Foley JA (1999) Estimating historical changes in global land cover: croplands from 1700 to 1992. Global Biogeochem Cycles 13:997-1027

Rosenzweig C, Casassa GK, Imeson A, Liu C and others (2007) Assessment of observed changes and responses in natural and managed systems. In: Parry ML Canziani OF, Palutikof JP, van der Linden PJ, Hanson CE (eds) Climate Change 2007: impacts, adaptation and vulnerability. Contribution of Working Group II to the Fourth Assessment Report of the Intergovernmental Panel on Climate Change. Cambridge University Press, Cambridge, p 79-131

Rosenzweig C, Karoly D, Vicarelli M, Neofotis P and others (2008) Attributing physical and biological impacts to anthropogenic climate change. Nature 453:353-357

Rutishauser T, Studer S (2007) Klimawandel und der Einfluss auf die Frühlingsphänologie. Schweiz Z Forstwes 158: 105-111 (English abstract)

Rutishauser T, Luterbacher J, Jeanneret F, Pfister C, Wanner $\mathrm{H}$ (2007) A phenology-based reconstruction of inter-annual changes in past spring seasons. J Geophys Res 112: G04016, doi: 10.1029/2006JG000382

Rutishauser T, Luterbacher J, Defila C, Frank D, Wanner H (2008) Swiss spring plant phenology 2007: extremes, a multi-century perspective and changes in temperature sensitivity. Geophys Res Lett 35:L05703, doi: 10.1029/

Submitted: July 12, 2008; Accepted: October 24, 2008
2007GL032545

Schaber JA (2003) The R pheno package: auxiliary functions for phenological data analysis. Available at www.r-project.org

Schaber J, Badeck F (2002) Evaluation of methods for the combination of phenological time series and outlier detection. Tree Physiol 22:973-982

Schleip C, Menzel A, Estrella N, Dose V (2006) The use of Bayesian analysis to detect recent changes in phenological events throughout the year. Agric For Meteorol 141: 179-191

Schleip C, Menzel A, Dose V (2008a) Norway spruce (Picea abies): Bayesian analysis of the relationship between temperature and bud burst. Agric For Meteorol 148:631-643

Schleip C, Rutishauser T, Luterbacher J, Menzel A (2008b) Time series modeling and central European temperature impact assessment of phenological records over the last 250 years. J Geophys Res 113:G04026, doi: 10.1029/2007 JG000646

Schüepp M (1961) Lufttemperatur. Langjährige Temperaturreihen. Beih Ann Schweiz Meteorol Zentralanst vol. 2

> Schwartz MD, Ahas R, Aasa A (2006) Onset of spring starting earlier across the Northern Hemisphere. Glob Change Biol 12:343-351

Siljamo P, Sofiev M, Ranta H, Linkosalo T and others (2008) Representativeness of point-wise phenological Betula data collected in different parts of Europe. Glob Ecol Biogeogr 17:489-502

Sneyers R (1995) Climate instability determination. Discussion of methods and examples. Proc 6th Int Meeting Stat Climatol, 19-23 June 1995, Galway, p 547-550

Sparks TH, Carey PD (1995) The responses of species to climate over two centuries: an analysis of the Marsham phenological record 1736-1947. J Ecol 83:321-329

Sparks T, Lines J (2008) Chapters in the life of Robert Marsham (1708-1797). Stratton Strawless, St. Margaret's Church

Sparks TH, Jeffree EP, Jeffree CE (2000) An examination of the relationship between flowering times and temperature at the national scale using long-term phenological records from the UK. Int J Biometeorol 44:82-87

Studer S, Appenzeller C, Defila C (2005) Inter-annual variability and decadal trends in Alpine spring phenology: a multivariate analysis approach. Clim Change 73:395-414

Studer S, Stöckli R, Appenzeller C, Vidale PL (2007) A comparative study linking satellite phenology to ground observed phenology. Int J Biometeorol 51:405-414

> Yiou P, Vautard R, Naveau P, Cassou C (2007) Inconsistency between atmospheric dynamics and temperatures during the exceptional 2006/2007 fall/winter and recent warming in Europe. Geophys Res Lett 34:L21808, doi: 10.1029/2007 GL031981

Proofs received from author(s): September 9, 2009 